\title{
The science of singing:
}

When speech and music combine

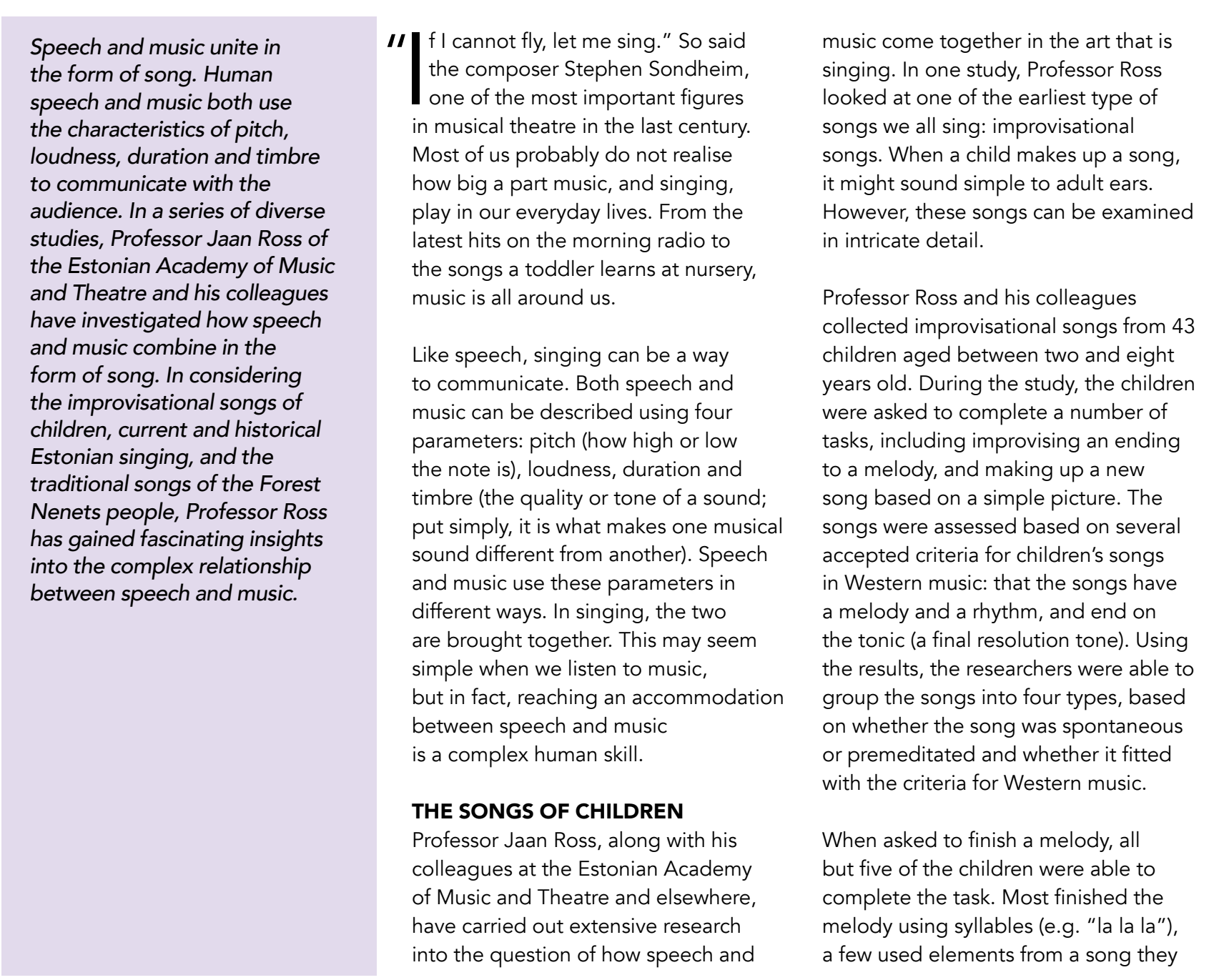

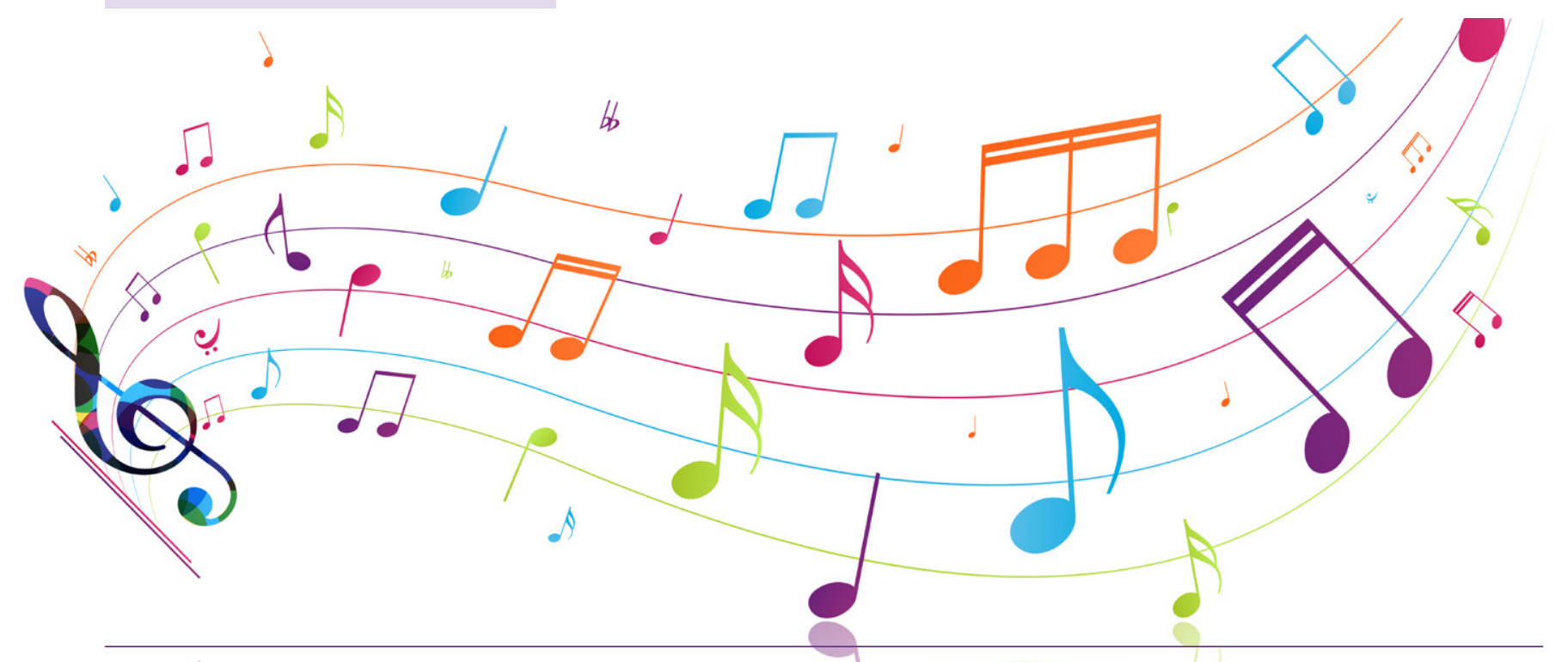

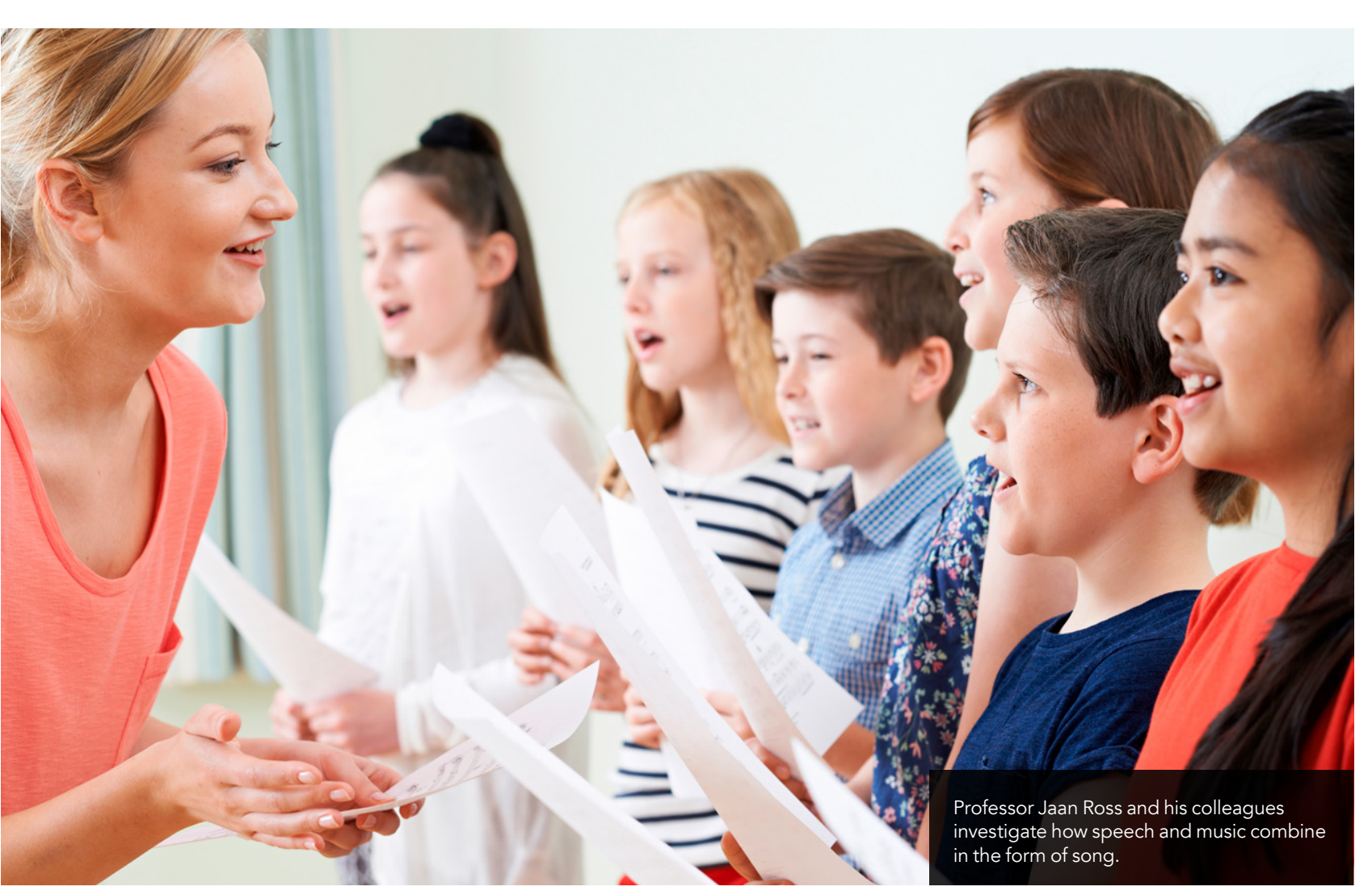

already knew and one child invented new lyrics for the song. In comparison, when asked to make up a song based on a picture, only 30 children completed the task. Impressively, 20 children invented a new song with original lyrics and melody, while seven thers sang a song they already knew hat they linked to one of the pictures.

Professor Ross and his colleagues believe that the different success to the fist task being lasks was due the other hand, the second required a series of steps (choose a picture, invent lyrics, invent melody). The children also showed a variety of different approaches to completing the song-inventing task. However, the results did clearly show that, by the age of four, most of the children in the study had not only picked up the rules for children's songs in Western music, but could also apply those rules to create songs of their own.

SPEECH AND MUSIC N ESTONIAN SONGS As an almost universal form of human expression, singing can be an effective way to communicate emotion. But study, Professor Ross measured syllable duration in the Estonian language. He compared syllable length in speech and in song. Syllable length, along with pitch, loudness to the expressiveness of a song.

Professor Ross suspected that some of the variations in vocal performances

Estonian is an interesting language to use in this work because it has an unusual property: it uses temporal variation to change the grammar and meaning of words, similar to the way that pitch variation changes meaning in some languages (e.g. Chinese).

Professor Ross and his colleagues decided to look at several aspects

\section{Reaching an accommodation between} speech and music is a complex human skill.

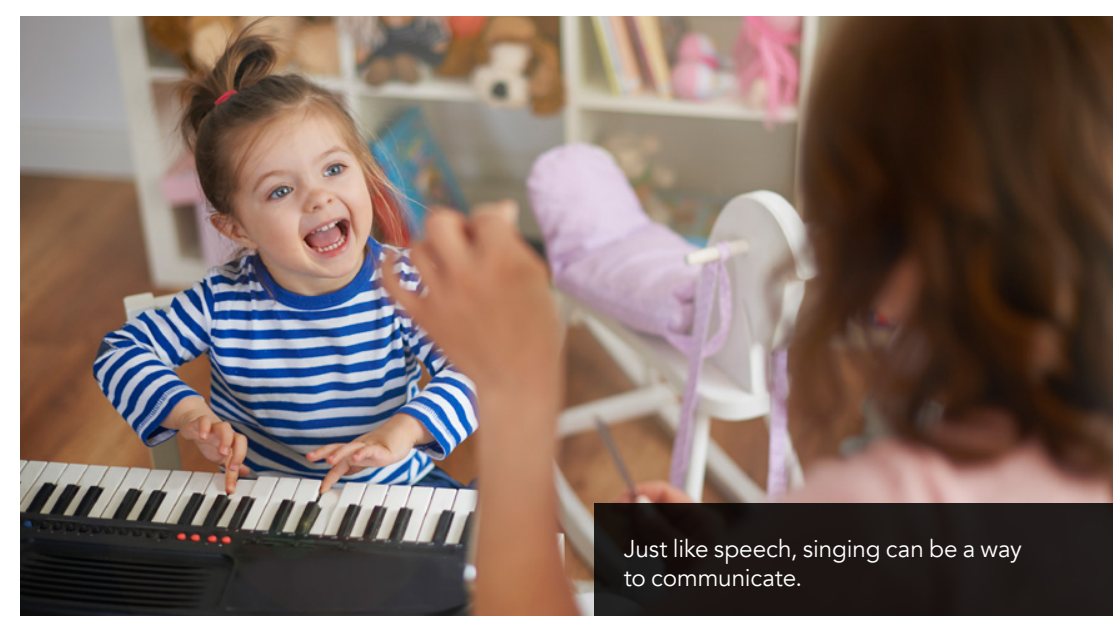




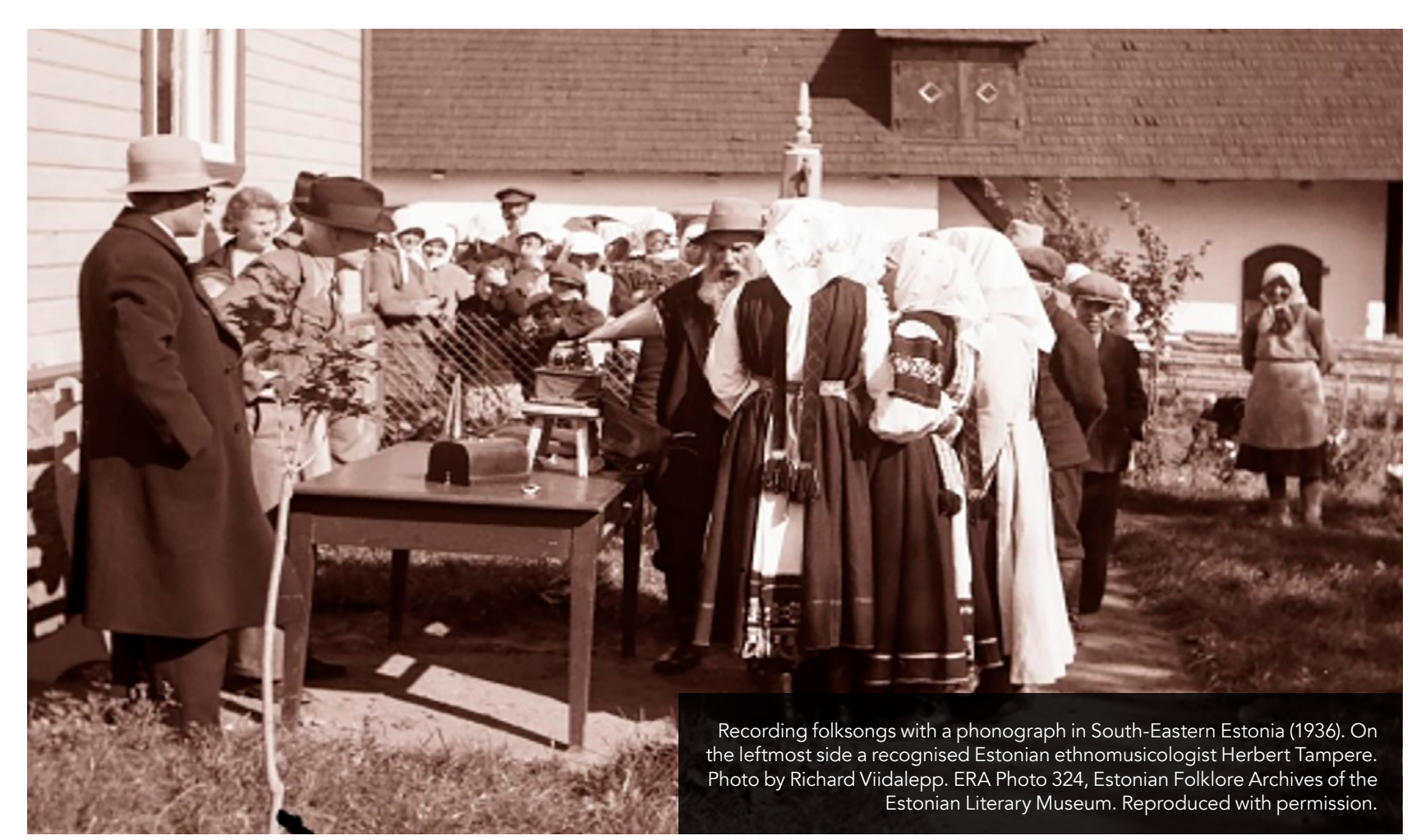

of this, they compared historical song recordings from 1916 with contemporary recordings. The histo
recordings featured three singers preforming popular Estonian folk songs in Germany in the early twentieth century. To ensure the same songs were used in the contemporary recordings, the team gave volunteers the lyrics and melody from the 1916 recordings, and asked them to sing the song

Professor Ross found that, as might be expected, long syllables had a greater duration than short syllables.

The vocal music of the Forest Nenets has its own unique characteristics, and does not fit within the defined rules of Western music tradition.

In a third study, Professor Ross and Triinu Ojamaa asked several participants to identify the boundaries between successive melody lines in tradition Forest Nenets songs. Participants included a member of the Forest Nenets, an Estonian composer and an Estonian ethromusicologist (someone who stud the music o f cherent culcures). The aim very different backgrounds, completed

to the audience. When asked if Forest Nenets singers ever made mistakes, he said, "How could you make mistakes when you know what you wish to say?"

Professor Ross concluded that few of the rules of Western music seem to apply to the traditional vocal compositions of the Forest Nenets.

SINGING UNITES

H AND MUSIC

The work of Professor Ross and

his colleagues has illuminated a number between speech

It seems that the greater the deviation and music and

compared to It seems that the greater the deviation how the two come speech. It also from the more rigid patterns of speech, together in the together in the $\begin{array}{lll}\text { appeared to vary the more expressive a song can be. } & \begin{array}{l}\text { torm of song. From } \\ \text { songs created by }\end{array}\end{array}$ song. Interestingly, young children to

the song with the most emotionally loaded lyrics differed most from the patterns seen in speech. It seems that the greater the deviation from the more rigid patterns of speech, the more expressive a song can be.

\section{THE SONGS OF THE}

FOREST NENETS

The For N Nents are an ethnic

group of fust 2,000 people who live in

the task in the same way. The researchers found that there were some similarities in the ways in which the participants approached the task. Both the Forest Nenets and the composer used the tex to complete the task, rather than the melody. Interestingly, however, when attempting to segment the songs, the composer almed for what he understo to be the "correct form. Conversely, purpose of the song as a story to be told ew thousand people, there are many diverse and fascinating ways to

approach the question. In considering , Prefessor Ross noted that the Wester Steppingsic are linited in scope. Stepping outside these rules, particularly cultures, could offer a route of other links between traditional music sustained by just a cultures, could offer a route to a better

\section{Behind the Research} Professor Jaan Ross

E: jaan.ross@gmail.com T: +3725226886 W: https://et.wikipedia.org/wiki/Jaan_Ross

\section{Research Objectives}

The research of Professor Jaan Ross explores language, speech science and acoustic analysi

\section{Detail}

Jaan Ross

Estonian Academy of Music and Theatre

Tatari 13

10116 Tallinn

Estonia

Bio

Jaan Ross studied musicology at the Moscow State Tchaikovsky Conservatory between 1986-87. In 1988 he defended his PhD (equivalent) in musicology at the Lithuanian State Conservatory in Vilnius, and defended a PhD in psychology at the Abo Akademi University in Academy of Music and Theatre.

Funding

- Research Support Scheme of the Open Society n, grant 1661/1999

- Estonian Research Council, grant "Performative aspects of music", 2013-18

- Enget financing via Estonian Ministry of Education structure, historic formation, and contemporary development", 2007-12

- In 2009, Social Sciences and Humanities Research Council of Canada funded a seven-year major collaborative research initiative known as Advancing Interdisciplinary Research in Singing (AIRS) - In 1992 Fulbright scholarship to the Ohio

State University

In 2006 Mellon scholarship to the Berlin Institute or Advanced Study

\section{Collaborators}

I deeply acknowledge collaboration with my coOjamaa, Marju Raju and Laura Välja for their extensive

\section{References}

Lippus, P. \& Ross, J. 2014. Temporal variation in singing as interplay between speech and music in Estonian songs. In: Expressiveness in Music Performance: Empirica approaches across styles and cultures. Eds. Fabian, D., Timmers, R. \& Schuber, E. Oxford University Press. doi: 10.1093/acprof:oso/9780199659647.003.0011

Ojamaa, T. \& Ross, J. 2011. The perceived structure of Forest Nenets songs: a cross-cultural case study.

Raju, M., Välja, L. \& Ross, J. 2015. Estonian children's improvisational songs, the nature of performance conerence with the Western tonal org/10.1177/1029864915598663

\section{Personal Response}

Which aspects of your research described her do you plan to expand on in the future?

II As mentioned above, in 2009, the Social Sciences and Humanities Research Council of Canada funded a seven-year major collaborative research initiative Singing (AIRS). The AIRS Test Battery of Singing Skills (ATBSS) was developed using a standard protocol appropriate for longitudinal testing of persons across the lifespan, from different cultures, and levels of musical training. The test has already collected a lot of data, many of them yet remaining unexplored.
This work should be continued. 